\title{
Adipokines and C-peptide in overweight and obese pregnant women
}

\author{
Elżbieta Poniedziałek-Czajkowska, Radzisław Mierzyński, Magdalena Słodzińska, \\ Dominik Dłuski, Bożena Leszczyńska-Gorzelak
}

Chair and Department of Obstetrics and Perinatology, Medical University of Lublin, Poland

\begin{abstract}
Objectives: The aim of the study was to evaluate the levels of adipokines such as adiponectin, resistin, leptin as well as C-peptide in overweight and obese pregnant women.

Material and methods: The adipokines and C-peptide concentrations were measured in the group of 38 overweight/obese pregnant women $\left(\mathrm{BMI}>25 \mathrm{~kg} / \mathrm{m}^{2}\right)$ and in 42 pregnant women of normal weight $\left(\mathrm{BMl}<25 \mathrm{~kg} / \mathrm{m}^{2}\right)$ with ELISA tests between $24^{\text {th }}$ and $34^{\text {th }}$ weeks of gestation.

Results: The overweight/obese women compared to lean ones were characterized by significantly higher concentrations of leptin ( $43.44 \pm 31.41$ vs. $21.29 \pm 12.67 \mathrm{ng} / \mathrm{mL}, \mathrm{p}=0.0001)$ and C-peptide $(2.77 \pm 1.88 \mathrm{vs.} 2.25 \pm 1.42 \mathrm{ng} / \mathrm{mL}, \mathrm{p}=0.034)$. There were no significant differences between groups in resistin ( $17.39 \pm 7.59 \mathrm{vs} .15 .76 \pm 6.64 \mathrm{ng} / \mathrm{mL}$, NS) and adiponectin $(6.93 \pm 3.52$ vs. $8.07 \pm 6.53 \mu \mathrm{g} / \mathrm{mL}$, NS) levels. In the overweight/obese patients, no relationships between the adipokines, C-peptide and CRP concentrations were found. BMI was negatively correlated with the resistin levels $(R=-0.406, p=0.011)$. The significant correlation between leptin and C-peptide concentrations was observed in the study group $(R=0.517$, $\mathrm{p}=0.012$ ). In the control group, the negative correlation between adiponectin concentrations and BMI was shown $(R=-0.446, p=0.003)$.

Conclusions: The higher levels of leptin in the overweight and obese pregnant women seem to reflect the leptin resistance condition and the higher levels of C-peptide in this group is suggestive for hyperinsulinemia. The positive correlation between C-peptide and leptin levels but not with resistin and adiponectin might confirm the role of leptin in the hyperinsulinemia development in overweight and obesity during pregnancy.
\end{abstract}

Key words: adipocytokines, C-peptide, obesity, pregnancy

Ginekologia Polska 2018; 89, 8: 442-448

\section{INTRODUCTION}

In the past few decades, a dramatic increase in the incidence of overweight and obesity in women of child-bearing age has been observed. According to the Australian data, it has been estimated that about $15 \%$ of women aged 25 to 34 years (the highest fertility age) were obese [1].

The overweight and obesity usually are defined in terms of the body mass index (BMI): BMI $\geq 25 \mathrm{~kg} / \mathrm{m}^{2}$ indicates overweight and $\geq 30 \mathrm{~kg} / \mathrm{m}^{2}$ - obesity. Overweight and obesity in pregnancy, even without chronic diseases before conception, are the risk factors of adverse obstetric and neonatal outcomes: the prevalence of gestational hypertension and preeclampsia, gestational diabetes mellitus (GDM), cesarean delivery, and labour induction increases. Similarly, neonatal risks rise up with the maternal BMI augmentation including preterm birth below $32^{\text {nd }}$ week of gestation, macrosomia, transient tachypnea, sepsis, and an intensive care unit admission [2].

Children of obese mothers are exposed to the development of the childhood obesity and metabolic syndrome in the adult life. A phenomenon described as "fetal programming" or "developmental origin of adult disease" refers to the abnormal intrauterine fetal development [3, 4]. The data indicate that adipocytokines may play a critical role 
in this process. The name of adipocytokine (adipokine) is given to any protein that can be synthesized and secreted by adipocytes. These molecules are involved in controlling and the regulation of the appetite and energy balance, the angiogenesis, inflammation, immunity, blood pressure, insulin sensitivity, glucose homeostasis, nutrient transport, and lipid metabolism. Their synthesis is altered in obesity, type 2 diabetes and metabolic syndrome [5]. Leptin, resistin and adiponectin representing adipokines family, all are known to be produced not only by adipose tissue but also within the intrauterine environment [6].

Leptin, the product of the ob gene, is involved in the regulation of energy homeostasis and is almost exclusively expressed and produced by the white adipose tissue [6]. The concentrations and adipose tissue mRNA expression of leptin are strongly associated with BMI and fat mass [7, 8]. The functions attributed to leptin are extensive, including the regulation of food intake and energy balance: it influences the inhibition of the insulin secretion, stimulates the glucose transport and acts as a signal to the reproductive system [7]. During pregnancy, the leptin levels are two- to three-fold higher than in non-pregnancy conditions with the maximum concentrations at $28^{\text {th }}$ week and the decrease to the pregravid values after delivery. The placenta is a significant source of the maternal circulating leptin, which is positively correlated with the fat mass during pregnancy [9]. Although the leptin levels typically correlate with adipose tissue mass, it has been shown that obese individuals had the elevated leptin levels without the expected anorexic responses. This observation could suggest the leptin resistance in obesity [10]. Pregnancy is considered a leptin-resistant state as well [11].

Resistin is believed to promote the insulin resistance by increasing the storage of triglycerides in muscles and the liver, instead of the adipose tissue [12]. It is also highly expressed in macrophages and monocytes suggesting that it may influence the insulin resistance via the inflammatory pathways [13]. The resistin levels have been shown to be negatively correlated to waist-hip ratio and positively correlated with body fat mass which would be consistent with a role of resistin in the insulin resistance development [14]. Opposite to this opinion, some studies do not confirm the correlation between the resistin plasma levels, BMI and the insulin resistance [15]. The resistin concentrations in pregnant women are significantly higher as compared to non-pregnant controls and increase as pregnancy progresses. It has been postulated that these levels correlate with the insulin resistance in the late gestation [16].

Adiponectin is considered as an insulin-sensitizing, anti-inflammatory and anti-atherogenic adipokine. It stimulates the glucose uptake in skeletal muscles and reduces the hepatic glucose synthesis [17]. The adiponectin concentrations are lower in obese and/or type 2 diabetic patients. The inverse correlation between the adiponectinemia and obesity, particularly the abdominal obesity, and the strong positive correlation between the adiponectin levels and the insulin sensitivity were observed. The results of experimental studies indicate the protective role of adiponectin against obesity-related metabolic diseases [18]. The adiponectin expression is inhibited by pro-inflammatory cytokines, hypoxia, and oxidative stress which all are conditions typically associated with obesity [19]. It has been observed that in pregnancy the maternal adiponectin secretion progressively declines [20]. It has been found that the plasma adiponectin levels and mRNA expression were negatively correlated with the fat mass. This observation may imply the association between the adipose tissue accretion and signals for lowering adiponectin production even in the absence of obesity.

C-peptide, the 31 amino-acid residues formed during cleavage of insulin from proinsulin, is released by the pancreatic $\beta$ cell in equimolar amounts with insulin. It is an independent marker of insulin biosynthesis and secretion [21].

The data analyzing the levels of adipocytokines in normal and complicated pregnancies are ambiguous. Recognizing the significance of adipose tissue and its hormones in terms of the appropriate metabolic control in pregnancy, we decided to evaluate the concentrations of adipokines such as leptin, resistin, adiponectin, as well as, C-peptide in overweight and obese pregnant women.

\section{MATERIAL AND METHODS}

Thirty-eight overweight and obese women (BMI > $>25.0 \mathrm{~kg} / \mathrm{m}^{2}$ ) and forty-two healthy pregnant women $\left(\mathrm{BMI}<25.0 \mathrm{~kg} / \mathrm{m}^{2}\right)$ were included to the study which was performed in Department of Obstetrics and Perinatology, Medical University in Lublin. All of them gave informed consent to participate in the study, which had been previously approved by the Bioethical Review Board of the Medical University in Lublin. The body mass index (BMI) was assessed based on weight measurement at the first prenatal visit before the $8^{\text {th }}$ week of gestation. The inclusion criteria for the study were as follows: gestational age between $24^{\text {th }}$ and $34^{\text {th }}$ week as determined on ultrasound before the $20^{\text {th }}$ week, first prenatal visit before $8^{\text {th }}$ week, singleton pregnancy. The exclusion criteria for the study were as follows: pre-pregnancy diabetes mellitus, chronic and gestational hypertension, preeclampsia, chronic renal disease, intrauterine growth retardation, liver diseases, inflammation and infectious diseases - the patients with a positive urine or vaginal culture were excluded from the study as well as cigarette smokers.

The oral glucose tolerance test (OGTT) with $75 \mathrm{~g}$ of glucose in compliance with WHO standards was performed in all women in the study and in the control group between $24^{\text {th }}$ and $28^{\text {th }}$ week of gestation. In the test day, glucose 
levels were measured fasting and at $1^{\text {st }}$ and at $2^{\text {nd }}$ hour after glucose loading. The glucose levels were measured in venous blood plasma with the use of glucose oxidase method (Cormay, Poland). The serum leptin, adiponectin, resistin, C-peptide and C-reactive protein (CRP) levels were assessed in all patients between $24^{\text {th }}$ and $34^{\text {th }}$ week of gestation. The blood samples were taken fasting together with samples for routinely performed laboratory tests. The samples were allowed to clot for at least 30 minutes before centrifugation at $1000 \mathrm{G}$, which was continued for 30 minutes. Serum has been removed and then frozen at $-70^{\circ} \mathrm{C}$. The leptin concentrations were measured by means of the sandwich enzyme immunoassay technique (Human Leptin Quantikine, R\&D Systems Inc. Minneapolis, USA) as well as adiponectin (Human Adiponectin Quantikine, R\&D Systems Inc. Minneapolis, USA), resistin (Human Resistin Quantikine, R\&D Systems Inc. Minneapolis, USA) and C-peptide (C-peptide, DakoCytomation Ltd Ely, United Kingdom). CRP levels were measured with ELISA method (CRP Elisa Kit Immunodiagnostik AG, Bensheim, Germany).

The study group was compared to the control one with respect of maternal and gestational age at the entry to the study, parity, BMI, CRP levels and glucose levels at each hour of OGTT as well as the leptin, adiponectin, resistin and C-peptide concentrations. The correlations between the leptin, adiponectin, resistin, C-peptide levels and BMI, and CRP concentrations were analyzed in the study and in the control group.

The Statistica 12.5 for Windows (StatSoft, Poland) was used for data analysis. The elements of descriptive statsistics were used. The data was presented as mean \pm standard deviation. The Shapiro-Wilk test for normal distribution of the data and one-tailed Student's t-test, or (in unequal variance) The Cochran-Cox test (absence of normal distribution and nonparametric data), and the Mann-Whitney $U$ were performed. The Spearman rank test was employed for searching correlations between variables. The statistical significance was defined as $p<0.05$.

\section{RESULTS}

The studied groups did not differ with regard to the baseline descriptors: age (30.42 \pm 5.31 vs. $29.24 \pm$ \pm 5.92 years, NS), gestational age $(29.13 \pm 3.16$ vs. $29.40 \pm$ $\pm 2.89 \mathrm{hbd}, \mathrm{NS})$. The BMI value was significantly higher in overweight/obese patients than in lean ones ( $\left.32.68 \pm 5.12 \mathrm{vs} .21 .07 \pm 2.13 \mathrm{~kg} / \mathrm{m}^{2}, \mathrm{p}<0.000001\right)$ as well as CRP concentrations $(12.69 \pm 27.15 \mathrm{vs} .6 .62 \pm 13.54 \mathrm{mg} / \mathrm{L}, \mathrm{p}=0.014)$. The glucose levels in OGTT at $1^{\text {st }}$ and $2^{\text {nd }}$ hour were comparable between groups ( $1^{\text {st }}$ hour: $162.00 \pm 37.10$ vs. $148.26 \pm 42.20$, NS; $2^{\text {nd }}$ hour: $146.91 \pm 42.65$ vs. $\left.129.07 \pm 45.80, N S\right)$; fasting glucose levels were higher in overweight/obese women $(91.44 \pm 18.14$ vs. $84.38 \pm 12.00, p=0.05)$, but the difference was not statistically significant (Tab. 1).

The patients in the study group compared to control one were characterized by significant higher concentrations of leptin ( $43.44 \pm 31.41$ vs. $21.29 \pm 12.67 \mathrm{ng} / \mathrm{mL}, \mathrm{p}=0.0001)$ and C-peptide ( $2.77 \pm 1.88$ vs. $2.25 \pm 1.42 \mathrm{ng} / \mathrm{mL}, \mathrm{p}=0.034)$. There were no significant differences between groups in the levels of resistin $(17.39 \pm 7.59 \mathrm{vs} .15 .76 \pm 6.64 \mathrm{ng} / \mathrm{mL}, \mathrm{NS})$ and adiponectin (6.93 \pm 3.52 vs. $8.07 \pm 6.53 \mu \mathrm{g} / \mathrm{mL}$, NS) (Tab. 2).

In the study group, no relationships between the adipokines, C-peptide and CRP concentrations were found. The BMI was negatively correlated with the resistin levels $(R=-0.406, p=0.011)$ and the positive correlation, not statistically significant, was marked with the leptin levels $(R=0.319$, $p=0.05)$. The significant correlation between the leptin and C-peptide concentrations was found in overweight/obese patients ( $R=0.517, p=0.012$ ) (Tab. 3). In the control group, only the negative correlation between the adiponectin concentrations and $B M I$ was shown $(R=-0.446, p=0.003)(T a b .4)$.

Table 1. The characteristics of overweight/obese and lean pregnant women

\begin{tabular}{|l|c|c|c|}
\hline & $\begin{array}{c}\text { BMI } \mathbf{2 5} \mathbf{~ k g} / \mathbf{m}^{\mathbf{2}} \\
\mathbf{N}=\mathbf{3 8}\end{array}$ & $\begin{array}{c}\text { BMI }<\mathbf{2 5} \mathbf{~ k g} / \mathbf{m}^{\mathbf{2}} \\
\mathbf{N}=\mathbf{4 2}\end{array}$ \\
\hline Age & $30.42 \pm 5.31$ & $29.24 \pm 5.92$ & NS \\
\hline Gestational age $(\mathrm{hbd})$ & $29.13 \pm 3.16$ & $29.40 \pm 2.89$ & NS \\
\hline Parity & $1.82 \pm 1.08$ & $2.00 \pm 1.15$ & NS \\
\hline BMI $\left[\mathrm{kg} / \mathrm{m}^{2}\right]$ & $32.68 \pm 5.12$ & $21.07 \pm 2.13$ & $\mathrm{P}<0.000001$ \\
\hline CRP [mg/L] & $12.69 \pm 27.15$ & $6.62 \pm 13.54$ & $\mathrm{p}=0.014$ \\
\hline Glucose $[\mathrm{mg} / \mathrm{dL}] 0^{\prime}$ & $91.44 \pm 18.14$ & $84.38 \pm 12.00$ & $\mathrm{p}=0.05$ \\
\hline $1^{\prime}$ & $162.00 \pm 37.10$ & $148.26 \pm 42.20$ & NS \\
\hline $2^{\prime}$ & $146.91 \pm 42.65$ & $129.07 \pm 45.80$ & NS \\
\hline
\end{tabular}

$\mathrm{BMI}$ - body mass index; CRP — C-reactive protein; $\mathrm{p}$ - statistical significance; NS — statistically not significant 
Table 2. The adipokines and C-peptide concentrations in overweight/obese and lean pregnant women

\begin{tabular}{|l|c|c|c|} 
& BMI & $\mathbf{2 5} \mathbf{~ k g} / \mathbf{m}^{2}$ & $\mathbf{B M I}<\mathbf{2 5} \mathbf{~ k g} / \mathbf{m}^{\mathbf{2}}$ \\
$\mathbf{N}=\mathbf{3 8}$ & $\mathbf{N}=\mathbf{4 2}$ & $\mathbf{P}$ \\
\hline Leptin $[\mathrm{ng} / \mathrm{mL}]$ & $43.44 \pm 31.41$ & $21.29 \pm 12.67$ & $\mathrm{p}=0.0001$ \\
\hline Adiponectin $[\mu \mathrm{g} / \mathrm{mL}]$ & $6.93 \pm 3.52$ & $8.07 \pm 6.53$ & NS \\
\hline Resistin $[\mathrm{ng} / \mathrm{mL}]$ & $17.39 \pm 7.59$ & $15.76 \pm 6.64$ & NS \\
\hline C-peptide $[\mathrm{ng} / \mathrm{mL}]$ & $2.77 \pm 1.88$ & $2.25 \pm 1.42$ & $\mathrm{p}=0.034$ \\
\hline
\end{tabular}

$\mathrm{BMI}$ - body mass index; $\mathrm{p}$ - statistical significance; NS — statistically not significant

Table 3. The correlations between adipokines and C-peptide and BMI and CRP in overweight/obese pregnant women

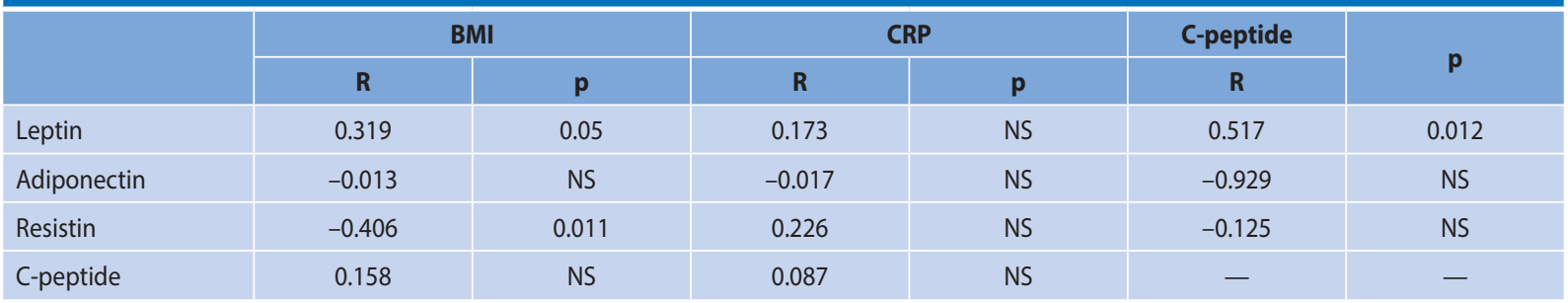

$\mathrm{BMI}$ - body mass index; CRP — C-reactive protein; R - Spearman correlation's coefficient; $\mathrm{p}$ - statistical significance; NS — statistically not significant

Table 4. The correlations between adipokines and C-peptide and BMI and CRP in normal weight pregnant women

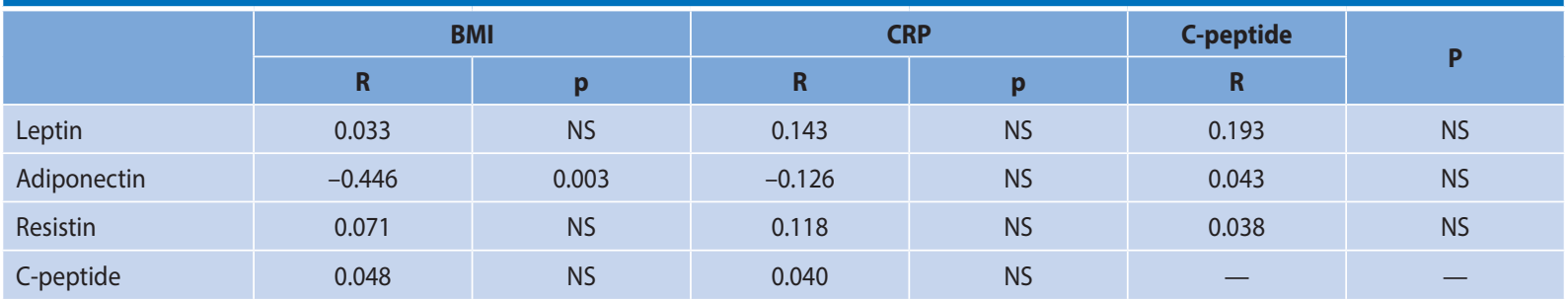

BMI - body mass index; CRP — C-reactive protein; R - Spearman correlation's coefficient; $p$ - statistical significance; NS — statistically not significant

\section{DISCUSSION}

The overweight and obesity are associated with adverse reproductive health outcomes although the exact mechanisms have not been identified yet. The human pregnancy is characterized by metabolic changes that promote the adipose tissue accretion in early gestation, followed by insulin resistance in late pregnancy. The maternal obesity and placental-derived hormones are believed to play the significant role in insulin resistance development as well as other pregnancy-related conditions [2].

In this study, the overweight/obese pregnant women and the normal weight women were compared in respect of the adipokines levels such as adiponectin, leptin and resistin. It has been found that the adiponectin levels were comparable in both groups. The same result has been achieved by Ozias et al. who shown no difference in the concentrations of adiponectin between the normal and overweight/obese women in the third trimester of gestation [22]. Other authors have reported that the overweight and obese pregnant women had decreased adiponectin levels compared to the patients of normal weight [23]. The possible discrepancy between the results of this and previous research might be explained by the different criteria of the study protocol. In this study, the BMI value was assessed based on the patient's weight before the $8^{\text {th }}$ week of gestation whereas other authors took into consideration the BMI value in different stages of pregnancy what included also the gestational weight gain.

In our study, the negative correlation between adiponectin and BMI was observed only in the lean pregnant women. These results are intriguing since the lower adiponectin levels are thought to be characteristic of obesity apart from pregnancy [24]. Our observations partially confirm the results of the study presented by Ritterath C. et al. who have found no correlation between the adiponectin concentrations and BMI in pregnant women. They have shown that adiponectin levels were negatively correlated with triglyceride levels. Thus they are of opinion that the decrease in the adiponectin concentrations in pregnancy might be more closely connected with the changes in fat metabolism than with an increase in the 
insulin resistance or the weight gain during pregnancy [25]. Another report has revealed that the adiponectin levels are strongly related to BMI in pregnant women at $24^{\text {th }}-29^{\text {th }}$ weeks of gestation but not to the glucose loading response [26]. In our study, no correlations between the adiponectin and glucose levels in OGTT in both groups have been found. Hence, a mechanism or factors maintaining the adiponectin levels in overweight and obese pregnant women could be postulated. This hypothesis might be confirmed by the observation that not all overweight and obese women develop GDM during pregnancy which is thought to be associated with significantly lower concentrations of this adipokine [27]. Cortelazzi et al. have found that the concentrations of circulating adiponectin were lower in patients with GDM as compared to healthy pregnant women regardless of pre-pregnancy BMI and the insulin sensitivity [28].

The study of Mazaki-Tovi et al. has revealed that the adiponectin levels during the $1^{\text {st }}, 2^{\text {nd }}$ and $3^{\text {rd }}$ trimester were comparable and were significantly higher than postpartum levels. The authors concluded that despite the increased insulin resistance as pregnancy progresses, there were no significant alterations in the adiponectin levels [29]. This may imply that the regulation of the adiponectin release during gestation is altered. The elevated gestational adiponectin levels could be consistent with the postulated increased "adiponectin resistance" during pregnancy.

In the presented study, it has been found that the overweight/obese patients were characterized by the significantly higher concentrations of leptin compared to the lean ones what has been also observed by other researchers. The marked but not statistically significant positive correlation between BMI and the leptin levels in overweight/obese patients has been reported as well. Verhaeghe et al. have shown that the plasma levels of leptin, as well as the CRP concentrations, were strongly related to $\mathrm{BMI}$ in pregnant women at $24^{\text {th }}-29^{\text {th }}$ weeks of gestation [30]. Similarly, Qiu et al. have revealed that the elevated leptin concentrations were positively correlated with BMI and the insulin levels. After adjusting for age and BMI before pregnancy, GDM had an independent direct correlation with leptin concentrations. Thus they have proposed that the leptin levels equal to or more than $20 \mathrm{ng} / \mathrm{mL}$ could be a useful marker in predicting the GDM development. Moreover, it appears that in early pregnancy hyperleptinemia, regardless of maternal adiposity, could be associated with an increased risk of GDM [31].

The results of the study published by Misra VK. and Trudeau S. have indicated that although overweight and obese women had significantly higher serum leptin concentrations than their non-overweight counterparts throughout pregnancy and these concentrations increased significantly across gestation for both groups, the rate of this increase was significantly smaller for overweight/obese women. The authors believed that factors others than the fat mass alone can influence the leptin concentrations in this group of patients [32]. This observation could explain the lack of significant correlation between the leptin levels in the overweight/obese as well as in the normal weight pregnant women and BMI in our study.

There are conflicting data about the resistin levels during pregnancy. In this study, there were no significant differences between the overweight and obese and the lean pregnant women in the term of the resistin levels although the significant negative correlation between resistin levels and $\mathrm{BMI}$ in the study group has been reported. The opposite results have been presented by Hendler I. et al. who have found no correlations between the resistin levels and maternal BMI in the third trimester of pregnancy [27]. Thus the discrepancy between the results could be explained by the different study protocols.

Megia A et al. have observed that patients with GDM had lower resistin levels than women with normal glucose tolerance. The association between low serum resistin levels and the diagnosis of GDM was independent of the degree of insulin sensitivity [33]. Some reports have revealed the higher serum resistin levels in the $1^{\text {st }}, 2^{\text {nd }}$ and $3^{\text {rd }}$ trimesters of pregnancy and in GDM compared to non-pregnant control group [28]. These findings suggest that higher resistin levels could be associated with the decreased insulin sensitivity or could mediate the state of insulin resistance present during pregnancy.

In the presented report, the study group was characterized by significantly higher CRP levels than in the control one but no correlations were found between CRP concentrations and BMI in both groups. There is an observation suggesting the presence of a chronic low-grade inflammation in obesity with increased levels of several circulating markers of inflammation like C-reactive protein (CRP), tumor necrosis factor-alpha (TNF-a), interleukin-6 (IL-6), and others [34]. The results of our study might imply that in pregnancy the degree of inflammation, although significantly marked in the overweight /obese women, is not influenced by BMI itself in a direct way. Neither in the obese/overweight pregnant women nor in lean ones, relationships between the adipokines and CRP were found, which might postulate that their release during pregnancy is not affected by low, chronic inflammation condition associated with obesity.

C-peptide, an independent marker of the insulin biosynthesis and secretion, seems to be a useful diagnostic tool in diabetology and related fields [35]. In this research, it has been observed that the C-peptide levels were significantly higher in the overweight/obese pregnant women than in pregnant women of normal weight what is suggestive for hyperinsulinemia in this group although there were no differences in glucose concentrations in OGTT test between groups. We could find no correlations between 
the C-peptide levels and BMI both in the study and the control group what might suggest that $C$-peptide release during pregnancy are influenced not only by overweight and obesity. The positive correlation between the C-peptide and leptin concentrations in overweight/obese pregnant women could confirm the results of previous studies that have postulated the hyperleptinemia as one of the reasons for hyperinsulinemia $[9,12,35]$.

\section{CONCLUSIONS}

The obesity in pregnant women is characterized by a higher concentration of leptin but not adiponectin and resistin. Thus it could be postulated that pregnancy has a similar influence on the synthesis and release of adiponectin and resistin in the overweight and obese as well as in lean pregnant women. Some mechanisms and factors preventing the changes in these adipokines levels might be considered. It may be presumed that adiponectin and resistin might not be considered as the only factors related to the development of pregnancy complications connected with overweight and obesity. The higher levels of leptin in the overweight and obese pregnant women seem to reflect the leptin resistance condition and the higher levels of $\mathrm{C}$-peptide in this group is suggestive for hyperinsulinemia. The positive correlation between C-peptide and leptin levels but not with resistin and adiponectin might confirm the role of leptin in the hyperinsulinemia development in overweight and obesity during pregnancy.

\section{Acknowledgement}

This study was supported by the Medical University of Lublin, grant no. 332.

\section{Disclosure}

The authors declare no conflict of interest.

\section{REFERENCES}

1. Australian Bureau of Statistics. Australian social trends 2007: Overweight and obesity. Cat. no. 4102.0. Canberra: ABS. ; 2007.

2. Kim SS, Zhu Y, Grantz KL, et al. Obstetric and Neonatal Risks Among Obese Women Without Chronic Disease. Obstet Gynecol. 2016; 128(1): 104-112, doi: 10.1097/AOG.0000000000001465, indexed in Pubmed: 27275800.

3. Lau C, Rogers JM, Desai M, et al. Fetal programming of adult disease: implications for prenatal care. Obstet Gynecol. 2011; 117(4): 978-985, doi: 10.1097/AOG.0b013e318212140e, indexed in Pubmed: 21422872.

4. Briana DD, Malamitsi-Puchner A. The role of adipocytokines in fetal growth. Ann NY Acad Sci. 2010; 1205: 82-87, doi: 10.1111/j.1749-6632 .2010.05650.x, indexed in Pubmed: 20840257.

5. Antuna-Puente B, Feve B, Fellahi S, et al. Adipokines: the missing link between insulin resistance and obesity. Diabetes Metab. 2008; 34(1): 2-11, doi: 10.1016/j.diabet.2007.09.004, indexed in Pubmed: 18093861.

6. Lappas $M$, Yee K, Permezel M, et al. Release and regulation of leptin, resistin and adiponectin from human placenta, fetal membranes, and maternal adipose tissue and skeletal muscle from normal and gestational diabetes mellitus-complicated pregnancies. J Endocrinol. 2005; 186(3): 457-465, doi: 10.1677/joe.1.06227, indexed in Pubmed: 16135665.
7. Ahima RS, Flier JS. Leptin. Annu Rev Physiol. 2000; 62: 413-437, doi: 10.1146/annurev.physiol.62.1.413, indexed in Pubmed: 10845097.

8. Song Y, Gao J, Qu Y, et al. Serum levels of leptin, adiponectin and resistin in relation to clinical characteristics in normal pregnancy and preeclampsia. Clin Chim Acta. 2016; 458: 133-137, doi: 10.1016/j.cca.2016.04.036, indexed in Pubmed: 27154800.

9. Henson MC, Castracane VD. Leptin in pregnancy: an update. Biol Reprod. 2006; 74(2): 218-229, doi: 10.1095/biolreprod.105.045120, indexed in Pubmed: 16267210

10. Balland E, Cowley MA. New insights in leptin resistance mechanisms in mice. Front Neuroendocrinol. 2015; 39: 59-65, doi: 10.1016/j. yfrne.2015.09.004, indexed in Pubmed: 26410445.

11. Ladyman SR, Grattan DR. Suppression of leptin receptor messenger ribonucleic acid and leptin responsiveness in the ventromedial nucleus of the hypothalamus during pregnancy in the rat. Endocrinology. 2005; 146(9): 3868-3874, doi: 10.1210/en.2005-0194, indexed in Pubmed: 15905318.

12. Wen F, Zhang $H$, Bao C, et al. Resistin Increases Ectopic Deposition of Lipids Through miR-696 in C2C12 Cells. Biochem Genet. 2015; 53(4-6): 63-71, doi: 10.1007/s10528-015-9672-2, indexed in Pubmed: 25962325.

13. Codoñer-Franch $P$, Alonso-Iglesias E. Resistin: insulin resistance to malignancy. Clin Chim Acta. 2015; 438: 46-54, doi: 10.1016/j.cca.2014.07.043, indexed in Pubmed: 25128719.

14. Rajala MW, Qi Y, Patel HR, et al. Regulation of resistin expression and circulating levels in obesity, diabetes, and fasting. Diabetes. 2004; 53(7): 1671-1679, indexed in Pubmed: 15220189.

15. Ayeser T, Basak M, Arslan K, et al. Investigating the correlation of the number of diagnostic criteria to serum adiponectin, leptin, resistin, TNF-alpha, EGFR levels and abdominal adipose tissue. Diabetes Metab Syndr. 2016; 10(2 Suppl 1): S165-S169, doi: 10.1016/j.dsx.2016.03.010, indexed in Pubmed: 27016887.

16. Yura S, Sagawa $\mathrm{N}$, Itoh $\mathrm{H}$, et al. Resistin is expressed in the human placenta. J Clin Endocrinol Metab. 2003; 88(3): 1394-1397, doi: 10.1210/jc.2002011926, indexed in Pubmed: 12629135.

17. Zavalza-Gómez AB, Anaya-Prado R, Rincón-Sánchez AR, et al. Adipokines and insulin resistance during pregnancy. Diabetes Res Clin Pract. 2008; 80(1): 8-15, doi: 10.1016/j.diabres.2007.12.012, indexed in Pubmed: 18291552.

18. Fruebis J, Tsao TS, Javorschi S, et al. Proteolytic cleavage product of 30-kDa adipocyte complement-related protein increases fatty acid oxidation in muscle and causes weight loss in mice. Proc Natl Acad Sci U S A. 2001; 98(4): 2005-2010, doi: 10.1073/pnas.041591798, indexed in Pubmed: 11172066.

19. Ouchi N, Kihara S, Funahashi T, et al. Reciprocal association of C-reactive protein with adiponectin in blood stream and adipose tissue. Circulation. 2003; 107(5): 671-674, indexed in Pubmed: 12578865.

20. Catalano PM, Hoegh M, Minium J, et al. Adiponectin in human pregnancy: implications for regulation of glucose and lipid metabolism. Diabetologia. 2006; 49(7): 1677-1685, doi: 10.1007/s00125-006-0264-x, indexed in Pubmed: 16752186.

21. Brandenburg D. History and diagnostic significance of C-peptide. Exp Diabetes Res. 2008; 2008: 576862, doi: 10.1155/2008/576862, indexed in Pubmed: 18509495.

22. Ozias MK, Li S, Hull HR, et al. Relationship of circulating adipokines to body composition in pregnant women. Adipocyte. 2015; 4(1): 44-49, doi: 10.4161/adip.29805, indexed in Pubmed: 26167401.

23. O'Sullivan AJ, Kriketos AD, Martin A, et al. Serum adiponectin levels in normal and hypertensive pregnancy. Hypertens Pregnancy. 2006; 25(3): 193-203, doi: 10.1080/10641950600912976, indexed in Pubmed: 17065040.

24. Yamauchi T, Kamon J, Waki H, et al. The fat-derived hormone adiponectin reverses insulin resistance associated with both lipoatrophy and obesity. Nat Med. 2001; 7(8): 941-946, doi: 10.1038/90984, indexed in Pubmed: 11479627.

25. Ritterath C, Rad NT, Siegmund T, et al. Adiponectin during pregnancy: correlation with fat metabolism, but not with carbohydrate metabolism. Arch Gynecol Obstet. 2010; 281(1): 91-96, doi: 10.1007/s00404-0091087-z, indexed in Pubmed: 19381664.

26. McLachlan KA, O'Neal D, Jenkins A, et al. Do adiponectin, TNFalpha, leptin and CRP relate to insulin resistance in pregnancy? Studies in women with and without gestational diabetes, during and after pregnancy. Diabetes Metab Res Rev. 2006; 22(2): 131-138, doi: 10.1002/dmrr.591, indexed in Pubmed: 16170833.

27. Hendler I, Blackwell SC, Mehta SH, et al. The levels of leptin, adiponectin, and resistin in normal weight, overweight, and obese pregnant women 
with and without preeclampsia. Am J Obstet Gynecol. 2005; 193(3 Pt 2): 979-983, doi: 10.1016/j.ajog.2005.06.041, indexed in Pubmed: 16157097.

28. Cortelazzi D, Corbetta S, Ronzoni S, et al. Maternal and foetal resistin and adiponectin concentrations in normal and complicated pregnancies. Clin Endocrinol (Oxf). 2007; 66(3): 447-453, doi: 10.1111/j.1365-2 265.2007.02761.x, indexed in Pubmed: 17302882.

29. Mazaki-Tovi S, Kanety H, Pariente $\mathrm{C}$, et al. Maternal serum adiponectin levels during human pregnancy. J Perinatol. 2007; 27(2): 77-81, doi: 10.1038/sj.jp.7211639, indexed in Pubmed: 17262038.

30. Verhaeghe J, van Bree R, Lambin S, et al. Adipokine profile and C-reactive protein in pregnancy: effects of glucose challenge response versus body mass index. J Soc Gynecol Investig. 2005; 12(5): 330-334, doi: 10.1016/j. jsgi.2005.02.002, indexed in Pubmed: 15979544.

31. Qiu C, Williams MA, Vadachkoria S, et al. Increased maternal plasma leptin in early pregnancy and risk of gestational diabetes mel- litus. Obstet Gynecol. 2004; 103(3): 519-525, doi: 10.1097/01. AOG.0000113621.53602.7a, indexed in Pubmed: 14990416.

32. Misra VK, Trudeau S. The influence of overweight and obesity on longitudinal trends in maternal serum leptin levels during pregnancy. Obesity (Silver Spring). 2011; 19(2):416-421, doi: 10.1038/oby.2010.172, indexed in Pubmed: 20725059.

33. Megia A, Vendrell J, Gutierrez C, et al. Insulin sensitivity and resistin levels in gestational diabetes mellitus and after parturition. Eur J Endocrinol. 2008; 158(2): 173-178, doi: 10.1530/EJE-07-0671, indexed in Pubmed: 18230823.

34. Das UN, Das UN. Obesity, metabolic syndrome $X$, and inflammation. Nutrition. 2002; 18(5): 430-432, indexed in Pubmed: 11985951.

35. Johansson J, Ekberg K, Shafqat J, et al. Molecular effects of proinsulin C-peptide. Biochemical and Biophysical Research Communications. 2002; 295(5): 1035-1040, doi: 10.1016/s0006-291x(02)00721-0. 